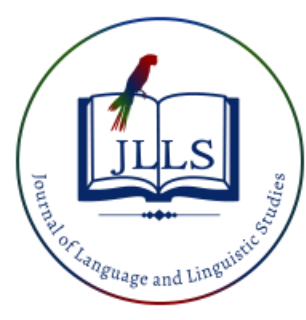

Available online at www.jlls.org

JOURNAL OF LANGUAGE AND LINGUISTIC STUDIES

ISSN: $1305-578 \mathrm{X}$

Journal of Language and Linguistic Studies, 17(1), 205-224; 2021

\title{
Methodology of literary text approaches in high schools analysis and models
}

\author{
Natasha Poroçani a 1 iD, Albana Deda ${ }^{\text {iD }}$ \\ ${ }^{a}$ University of Durrës, Albania \\ ${ }^{b}$ University of Tirana, Albania
}

APA Citation:

Poroçani, N., \& Deda, A. (2021). Methodology of literary text approaches in high schools analysis and models, Journal of Language and Linguistic Studies, 17(1), 205-224. Doi: 10.52462/jls.12

Submission Date: 06/01/2021

Acceptance Date: 14/03/2021

\section{Abstract}

In this paper, we have reviewed and analyzed literature textbooks at the pre-university level, respectively in the high school. In this research, we have examined the way these texts are analyzed (the pedagogical apparatus as it is otherwise called). Such work is done considering the requirements of the latter to fulfill certain competencies provided by the program on which the text is drafted.

The method we used is based on two parallel directions. One is about the aforementioned comparison of the required competencies and those realized in the pedagogical apparatus of the textbooks of different publishing houses, which have gained the right to be part of the textbooks that can be selected by different schools for the treatment of the subject of literature. This is seen according to the rubrics provided by the program, those currently implemented, and the competencies suggested by us, which we do not see implemented by the first two.

In parallel, we have identified the problems in terms of simple text analysis, in a stylistic, pragmatic-reflective plane, giving our suggestions for each case. About $80 \%$ of the textbooks show problems with the way the rubrics are constructed and almost $90 \%$ of the rubrics are constructed with questions that may go beyond the rubric topic.

The paper is accompanied by a concrete example of text analysis suggested to the professional network of literature teachers. This model is based on the experience of Italian and French textbooks.

Keywords: competence; rubric; stylistic analysis; pragmatic analysis; reading to understand; reading to analyse; reading to reflect; etc.

\section{Introduction}

Regarding the problems of language connection with literature and the interrelationships between them, more than a few cases have reflected problems that go beyond two specific areas, implying the dimensions of the study where we mostly encounter perceptions related to the conceptualization of language and literature in the era of globalization. This perceptual and conceptual orientation is

${ }^{1}$ Corresponding author.

E-mail address: natashaporocani@uamd.edu.al 
dedicated to the new situation offered thanks to the cultural openness to world dimensions and requires an obvious change to the old habits (G. Benvenuti \& R. Seranni, 2012, p 164).

\subsection{Literature review}

The new situation, in not a few cases, has prompted new forms of research towards comparative and deductive methods to explore literature and language in general along with the communicative function they fulfill in a global world. With this statement, we refer, among others, to the Institute of World Literature (IWL) ${ }^{2}$, at Harvard University, which in addition to researching the field in a universal framework, offers specific ways and courses to train teachers, to facilitate this process in order to provide a broad base in the global perspective. The researcher and director of this institute, concurrently serving as professor of comparative literature at Harvard University, David Damrosch, has long brought to the formation experience of this institution essays, guides, and anthologies that aim to include in the teaching process the concept of world literature (D. Damrosch, 2003), affirming the challenges encountered in this essay, the hardships that refer to the cultural boundaries of the peoples that produce this literature, the students as receptors in different times and spaces from the times of writing, the manner in which it is transmitted to the student. A vision of the world is always a vision driven by the situation in which the observer finds themselves and we inevitably filter what we read, through the experience of what we have read in the past (D. Damrosch, 2009). This filtering process is first and foremost a process of simultaneous reading, understanding, and interpretation.

But literature itself is enlivened through the word. To quote De Mauro (2002) "not every word lives in solitude. Its connection with others is enabled through form, meaning, subsequent use, connections with the experiences to which it relates. Above all, with its presence, the word strengthens the memories with which it is associated".

\section{Method}

\subsection{Samples and procedure}

In order to induce all approaches as clearly and convincingly to the target groups regarding the topic under discussion, we have preferred to use a comparative method during our work.

Firstly, we have gathered the necessary literature upon which our work will be developed and analyzed. Grade 10 literature texts are the starting point of this work (being followed by textbooks of other levels).

The gymnasium level of learning was selected, as we determine that at this level the corpus of knowledge obtained in the earlier years must have created the necessary cognition to achieve a high perception of both the meaning of literary texts and their structure.

In this context, the apparatus for the (pedagogical) analysis of literary texts in these books were initially reviewed and approached. Initially, the sections were taken from each text of each publishing house (Albas, Pegi, Filara ${ }^{3}$ ) were compared and the advantages and problems observed in them were identified.

Secondly, we have entered the research of the organization of the glossary by comparing to one another all the different approaches and discovering all of their strengths and weaknesses.

\footnotetext{
${ }^{2}$ https://iwl.fas.harvard.edu

${ }^{3}$ The process of drafting and publishing in Albania is organized as follows: Different publishing houses compile their literary texts in MARS. These texts are presented in the competition organized by MARS. The latter selects three winning texts, which meet the criteria set by it and are exactly these texts that must be circulated in schools.
} 
The entirety of this methodology was based on a reference model which at the end of the material is issued to interested groups as an example of an analysis that would lead to reading, understanding, analyzing, interpretation, and creation. Of course, with this model, we do not want to eliminate the analytical and interpretive peculiarities that specifically induce each text separately as part of an individual creative laboratory.

The model we offer comes because of the methodologies applied in several different countries, as well as the result of the experience of the two authors both in the theoretical aspect of literary analysis and pedagogical reflection and research at this level of study (Other theories have aided in this analysis: L. Tahiri \& N. Muhaxheri, 2021).

The glossary provided in this model is given in detail with sub-classifications, in order to create a clearer idea of the analysis and above all, to give a clear picture of its functionality in favor of the analysis of the groups of interest (They reflect the aim of competency-based learning. In this context we first analyze the evolution of the concept of competence and our perspective on this concept.).

This model aims to not only combine elements related to the cognition of the text but also manages to decipher the inter-text and identify the sociolinguistic and sociocultural influences on the matter.

Furthermore, through this model, we aim to give an interconnection of the decoding of the above elements by highlighting the typical structures ${ }^{4}$ which have been used as the main tools of text construction. The latter should not be identified simply as deviations in our perspective, but it should also be related to their meaning and to both the individual and collective effects induced by the text.

Such a thing could easily be identified in all the topics which are seen as a collective, connected, in cooperation and non-repetitively.

So the idea is for the analysis to be seen not merely as a dry identification of the main elements of the fable and the figuration used for this and perhaps in the best case of free and subjective interpretation of the most visible elements of the text, but also as an analysis of the depth of meanings that the text induces, the way they are achieved, the student's orientation towards finding and interpreting them analytically and not as knowledge supplied by the teacher, as well as giving the latter (student) the opportunity to analyze, reflect and create the same procedure by themselves, starting from the analysis made by them in collaboration with the teacher (who has an important role in class (Sarıçoban \& Kırmızı, 20215). So, this experimented model based also upon the Italian tradition targets a student's critical skills of text analysis and above all encourages them regarding the interpretation (interpretations), presentation, and of course, creation of such texts.

\subsection{Analytical description of learning development in the Albanian school}

The learning process of the language and literature in the Albanian school, but also necessary in the world, has gone through several phases of organizing the teaching and learning process, which have acquired throughout their evolution problems mostly related to the transition:

- from monolingual and mono-literary studies to multilateral and multicultural ones;

\footnotetext{
${ }^{4}$ We allow ourselves to suggest like thin considering our experience through the years.

${ }^{5}$ The authors in their paper stress the fact that the teacher of L2 has an important role in the acquisition of knowledge of the students. They give evidence of potential correlations between and among pre-service EFL teachers. They have observed particularly, as for the correlation between the sub-dimensions of epistemological beliefs and instructional preferences, that the ability to lean and source of knowledge dimensions was influential on transmission-based teaching epistemological cognitions, perceived engagement levels, and instructional preferences.
} 
- from isolated studies in the respective fields (language and literature) to integrated studies, through which language and literature are considered components of a relationship, during which human experiences are embedded and lived in processes of spreading truth through discourse forms;

-from learning based on monocultural identity ${ }^{6}$, towards a global linguistic and literary study, in which cultural boundaries are often merged with those of other fields;

-from a closed study, in which the canonical criteria matched the ideological ones in an open system is therefore always endangered by the inconsistent delimitation of the boundaries between two different disciplines (language and literature).

Now, in the 21st century, when globalization has been over imposed by technology and its instruments, the process of learning the language and literature in school, the identification of mechanisms used towards textual approaches of different typologies and styles set a challenge for both the programmers of textbooks as well as linguists and literary scholars, whose task remains to design uniform mechanisms of approaches to discourse analysis. In other words, equipping students with the mechanism of access to text and style.

If with literature lessons in school (from grade 2 of CU to grade 12 of HSE), we refer to a formative space through which the student not only studies literature but through literature they also receive information on different fields, in which the highest form of use of the mother tongue prevails, thus we have necessarily accepted the necessity of the aforementioned mechanism, which will enable the approach that meets all the above conditions. The dependence of the multiple connections of knowledge that we have as an object with social practice implies other categories of cognition, such as the historical category, which further emphasizes the above statement that teaching, reading, and understanding, evolves based on conditions such as social, cultural, historical and ultimately, technological. This finding of prof. T. Plangarica (2018) examines it in relation to the context in which the perspectives of teaching and learning the Albanian language will be obtained and the methodological directions that enable it more secure developments. We notice that this context close in time and experience appears as a mosaic, fragments of which sometimes lead to interesting experiences and functional teaching models, and other times leave you somewhat unclear or push you to search for the unspoken meanings yourself; sometimes to remember and be enthusiastic about the approximation of the values that are intended to be conveyed and other times to lead to despair for the lack of courage and traditionalism in treatment.

In the horizontal dimension ${ }^{7}$ of this context we include, among others, teachers, and textbooks for at least two reasons: because they moderate with specific paths with high sensitivity, the transition from knowledge to the individual (in our case the student), and are two standard capacities to achieve sufficient literacy student culture.

According to Serianni (L. Serianni, 2019) "teachers should also represent other areas of interest. They should also follow other non-simple things, e.g. What is art, since in technical and vocational schools (e.g.) there is no specific subject to address this field".

\footnotetext{
${ }^{6}$ As we will explain below, there have been and still are cases of monocultural studies, in which the cultures of peoples or their literary and linguistic segments, fail to integrate and are understood by other societies. So, they will remain the private property of the peoples who gave birth to them.

${ }^{7}$ In our view, the comprehensive context of teaching will be conceived in horizontal and vertical dimensions. In the vertical dimension, the context has the flexibility of a kaleidoscope within which all other mini-contexts such as social, cultural, personal, etc. come to life and create images. While the horizontal dimension focuses on instruments that have some consistency in the teaching process, while they are the ones that represent the longterm sustainability of this process: teachers, textbooks, didactic tools, solidified forms that can appear as individual instruments.
} 
To the conclusion that Serianni places in vocational schools, we add the comprehensive spaces of teaching literature in Albania: schools of any level, of any direction, and in order to be more oriented to the objective of our work, we single out the gymnasiums, which include the largest number of students enrolled in Higher Secondary Education ${ }^{8}$.

Through the knowledge of literature the student also receives knowledge from history, which requires and guarantees a surplus of historical preparation of teachers and textbooks; takes on forms of classical culture evoking very flexible themes; takes genuine aesthetic categories derived from the ancient philological basis, receives discourse reports of language use and etalons of their variables with the standard; forms and develops individual criteria on discourses that will determine his later status, standardizes philosophical directions through which he will orient his life, etc.

Therefore, the language and literature class does not exclusively concern the learning of either the language or literature separately.

In order to ensure effectiveness in the weight that this teaching space carries, a semantic, lexical, pragmatic, and stylistic reflection on the pedagogical apparatus that accompanies the fragmentary literature textbooks in the high school textbooks, would lead us to the strengths and weaknesses that the system grasps at its most sensitive point: a literary commentary.

Furthermore, with the scope of being analytical in the curricular expectations in the face of literary commentary ${ }^{9}$ we regard the start of the project by the terminological clarification of the two links of teaching and learning, which stick to each other in derivative relations: competence and language competence.

\subsection{The theoretical concept of competence}

Franca Da Re (2013:8) describing the evolution of the term competence gives us the three main references that most scholars approach:

1. Competencies as a set of parts which include capacities, skills, and knowledge (this opinion is supported by Levati \& Saraò (1998) and we also find it is a guide on field terminology in the Emilia Romania area (Glossario..., 1997).)

2. Competence as performance, as the ability to appear in the organizational plan and not as an integral element of the person. This approach is found mostly in British studies. Even Spencer (1995) sees competence as a concept composed of motivation, social cognition, and skills, etc.

3. The third approach to the term competence sees it as an act of mobilizing the person towards the problems he/she encounters (OCDE, 1996; G. Le Boterf, 1994). Da Re emphasizes that competence as a concept is already viewed as consisting of both didactic and classroom strategy and techniques. (She mentions traditional competencies such as frontal learning and exercises, contextualizing concepts, evaluating the student's experience through proposals for solving problems encountered, managing these situations, and individual and group responsibility concerning them, learning in social and cooperative contexts to extract in few cooperative capacities, etc.).

\footnotetext{
${ }^{8}$ According to INSTAT, the number of students enrolled in Higher Secondary Education for the school year 2019-2020 was 108,061, of which 89,869 are students enrolled in gymnasiums and socio-cultural schools. Sociocultural schools have a unified Albanian language and literature curriculum with gymnasiums. http://www.instat.gov.al/al/temat/tregu-i-punës-dhe-arsimi/arsimi/\#tab2 https://ascap.edu.al/ëp-content/uploads/2019/01/Gjuhë-shqipe-3.pdf ${ }^{9}$ Literary commentary will be considered another teaching instrument, but already in the vertical dimension if its flexibility varies and is conditioned by several factors, both linguistic and generative. By the latter, we understand the hierarchical dependence of text analysis structures on text segments, macro texts, micro texts, and hypertexts.
} 


\subsubsection{Literary competence}

In this paper, we will focus more specifically on literary competence. Regarding the latter, we refer to the definition we find in the work of Carla Sclarandis ${ }^{10}$.

It is defined in relation to the interpretive ability of texts, the ability that is acquired through specific learning in which texts are manipulated and in different ways are used by the interpretive reader.

Such a definition allows for an expansion of the student's analytical, research, and interpretive activity.

In this context, from the practical point of view of the establishment of the pedagogical apparatus of literary texts, we determine that the competence should provide for three ways of proceeding:

1. formal and linguistic work on textbooks;

2. interpretive dialogue with students and between students regarding the actualization of their meanings;

3. historicization of expressive forms ${ }^{11}$ and the ideology content they consist of.

The interpretation of the text implies a second focus, that of the interpreting-reader, with their prior knowledge and experience. Also, it presupposes the established learning methodology, in which social networks set up by web 2.0 insist as a learning function (Social Go or Classroom 2.0), the effectiveness of which seems to have already been established.

\subsubsection{Language competence}

Within the communicative reality, within which the school environment precedes as a standard in the formation of the individual, the definition of language competence achieved through the literature curriculum, entails not only the connection of the two fields, but it also inserts other phenomena in which the fields themselves are integrated as such. In order to be able to approach these formative modalities, clarity in defining language competencies but be established. According to Chomsky (Chomsky, 2006, p.102), since the language in use is not simply a set of phonetic and semantic properties, but also other factors such as extralinguistic relations concerning the speaker and the situation, which play a fundamental role in determining how a text is produced, identified and understood. As noticed, the aspects of psycholinguistics, sociolinguistics, etc. are disregarded.

Concurrently, Springer connects language competence with several processes which begin with mastering the language code and the practice of using language in situations of natural communication. These components are offered by the school to some extent, but according to Springer, the product that is expected to be achieved by the end of the school cycle should be clarified: the type of language status expected to be achieved; the thresholds of language competence levels, etc. The notion of "competence" as such it is reviewed, remodeled in dealing with these issues: it takes on the meaning of training in the acquisition of language skills, with all that this implies: research, union, awareness. The space devoted to these processes occupies a large part of the time previously reserved for the arrangement of language structures (Chomsky, 2006, p. 44).

Thus, we will talk about reception activities (listening, reading, audio-visual reception), production (speaking, writing), interactive activities (dialogue, written correspondence), mediation (translation, interpretation), new categories that go beyond separation classic in four skills.

\footnotetext{
${ }^{10} \mathrm{https} / / /$ site.unibo.it/griseldaonline/it/didattica/carla-sclarandis-letteratura-italiana-nuovi-italiani

${ }^{11} \mathrm{https} / / /$ site.unibo.it/griseldaonline/it/didattica/carla-sclarandis-leopardi-scuola-competenze ${ }^{12}$ https://shqiptarja.com/lajm/analiza-e-dy-pedagogeve-ku-qendronin-gabimet-ne-provimin-matures-se-gjuhes-eletersise
} 
Referring to Springer's view on the notion of language competencies complemented by several components, we would consider several components as components of language competence: mastery of the language code; knowledge of discourse forms in natural communication situations; understanding the highest degree of message content; reproducing messages in other contexts.

Both types of competencies that we listed, being integrated into models adapted by teachers, merge into the perceptions and critical view of the student, which is processed in two pedagogical orientations:

First-Competencies to be acquired from the literary commentary:

a) Linguistic (Descriptive knowledge of the code in general, as the main basis of cognition in general and various variants.)

b) Communicative, socio-cultural (the knowledge of which helps place messages in the right cultural, mental, social spaces, etc.)

c) Pragmatic conversational competence (strategies for constructing and interpreting different discourses), functional (realization of intended communicative functions and goals).

d) Interpretive-reflective and reconstructive competencies of the system of signs and codes.

Second- Types of reading that will provide these competencies:

Reading $\mathrm{I}=$ meaning

Reading II = deciphering and structuring

Reading III = interpretation and identification of stereotypical means

Reading IV = reflection and retrieval in other contexts

\section{Results identified in Literature textbooks, Grade 10}

In the Albanian education system, reformed since 2016, MARS (MESS) has approved three alternative texts, which have already been identified by publishing firms (Hamiti, Marashi \& Shehri, 2017), which have been in the hands of students and teachers for three years.

Referring to the processes through which the literary text will be treated, intending to realize the competencies that we have set out, we determine that reading as a basic process should be conditioned by two determining goals: understanding the lexicon and reading to learn. Perception provided by the meaning of the lexicon enables the student in several main directions: enabling the individualization of specific information; understanding information that the text infers; evidence the relations of cohesion and coherence; integrating and connecting an expanding information chain; reconstructing the overall meaning of the text; interpreting and evaluating the text.

Meanwhile, the second goal manages to provide competencies that appear in the student's ability: reading and understanding the signs of a text (format of a text and its content; organization of arguments in a text); the structure of a page; the transition from text to scaling to an oral presentation.

These links in the process will inevitably go through style and rhetoric analysis, in accordance with the specifics of the text, case by case for a textbook.

\subsection{Textbook of Albas}

The models of pedagogical apparatus offered by Albas' text are two: the first model, called Reflecting, aims to involve the student in reflective processes regarding the meaning, interpretation, 
structure, and language of style. It is supplemented by two sections involving expressive reading, writing, and vocabulary work.

The second model has two variants: Discuss and comment and Discuss and reason, variants that go to fit the specificity of the passage understanding the content and aim to establish the connection with its interpretation.

In the Reflecting section, Albas's text directs reflection towards meaning, interpretation, structure and language, and style. Thirteen literary texts are analyzed, of which five are poetic texts, three narrative texts, and five dramatic texts.

The text relies on the analysis of meaning reflected in the use of verbs: retell, find, reformulate, narrate. We determine that the glossary relies on the retelling of the content, referring to the division of the fragment into parts, either of the isolation of verses or sayings, through which the student percepts the individual meaning transmitted by the first read-through or derived from reading between the lines. The first read-through matches the evaluation of the content and creates the opportunity for reflection of the parts of the textual material provided.

Albas connects the meaning with the history of the fragment; strings/fragments within the fragment; character portrayal. Reflection on interpretation creates two standards: at first glance, the requirements for interpretation pass from semantic evidence to interpretive ones, as often breaks are created from the first topic since interpretation does not focus on the phenomena in which the student managed to identify by meaning, but subject to other excerpts from the text. e. g. the commentary of parts Orpheus and Eurydice (Albas, p. 43):

Reflecting on the meaning: What are the two passions of Orpheus? What can Orpheus do with his lyre? Regarding the interpreting question, this logically proceeds with the analysis of students: Reflecting on interpretation: In Greek mythology, Orpheus has a place of honor. He is part of the myths on cultural heroes... What are the messages of this myth?

But in many cases the continuity of the analysis is interrupted, transferring the student's attention to other key textual points, which are not related to the meaning: in the analysis of the passage from the Medea tragedy, the text step by step follows the cohesion of the work by placing the student semantic escalation, which runs parallel to the dramatic load, but the reflection sends the learner to other fields of interpretation: Reflecting on meaning: Medea's assessment; the connection of the verses with Medea, the feelings of Medea, the relationship with Janson, the condition of the woman. These are semantic focuses. While the reflection focuses on the evaluation and interpretation of Medea's thoughts regarding the nature of man, marriage, and Greek customs, etc.

\subsection{Textbook of Filara}

The textbook by Filara has dealt with twenty fragments, of which eight belong to the poetic text, seven to the dramatic text, and five fragments to the narrative text. The verbs used are identified, paraphrase, find. In line with our conclusions, the verbs identify and find in parts of the meanings also appear as synonyms, so it could be assumed that another verb should have been sought even as a term.

The pedagogical apparatus is built in this form:

Meaning of the text

Text analysis

\section{Linguistic interpretation and commentary}

The main problem relates to terminology and its semantic inconsistency. The analysis of the text and the interpretation of the commentary create chaos towards the purpose of the exercise because they fail to clarify the analytical criterion of the passage. This terminological overlap reflects a lack of 
coherence and ambiguity in the type of analysis to be performed, as long as both sections have converging goals. While poverty and terminological ambiguity has derived the impossibility of coherence of requirements.

The questions in the passages require re-identification of utterances, which leads the student to the first reading and does not bring any extra skills other than the first expressive comprehension plan. For example, (Gjergj Elez Alia-Folklore) The conflict of the song is related to the figure of Bajloz. Distinguish the verses where this is expressed (p. 74) / (Iliad-Homer) Find the comparisons used in the passage. (p. 95)

Also, textual coherence in identifications is not maintained, not respecting the chronology of the content. (Stuck Prometheus-Aeschylus) Question 8 sends the student to the first word of Prometheus: \{Identity in the words of Prometheus an antonymous couple that gives the essence of the dramatic contrast between them and Hermes (f. 110)\}, whereas question 9/c turns the attention back to the words of Hermes: Find the opposite words to those of Hermes that characterize Prometheus. (f. 111)

The analysis of the text is conceived in the following directions: defining the compositional construction for dramatic narratives and texts and semantic re-identification in poetic texts. The analysis included the description of the characters or the lyrical hero: the question What do the legends tell about the figure of Skanderbeg? (p.166) is preceded by the analysis of the real values of the work of Marin Barleti, while referring to the legendary-ness of the figure of the national hero; descriptions of action or feeling, identification of characters through retrospective actions.

Question: Why in these situations is it necessary to give speeches before the fighters? How do you react to these cheers? Give your reasons for the enthusiasm of the fighters. (f. 91), continues with the analysis of literary figures without creating logical continuity with the progress of text analysis, which aims to ensure the phenomenon of cohesion, but without success, because they do not connect the following logic of questions.

As for the third part, the interpretation returns to the phenomenon of meaning and identification. This is complemented by some connections and interpretations of rhetorical figures, but this finding used creates fragmentation and passive overload with the knowledge that is not used in deciphering either the message or the distinctive stylistic structures. We say that finding figuration in a text detached from its stylistic function for us is a functionless identification, which does not help in the intentional compositional identification created by the author.

\subsection{Textbook of Pegi}

Even in the textbook Pegi we note that the division into sections is standard for all texts. In the beginning, general information is given about a certain period, or a certain author, the biography of the latter, so it is aimed at an interdisciplinary knowledge, which we determine as a good thing. The verbs that appear most during these rubrics are: order, explain, define and find. (It should be noted that in many cases they are positioned in the rubrics, which in fact are not part of what they express.)

This treatment is accompanied by a Text Study section, in which we determine that questions are asked which require more testing of the student's memory on a mimetic lesson of the information given, without leaving them any possibility of individual interpretation supported even in parts very small texts given even for illustration. At this level, this type of teaching is unacceptable and contradicts the learning that focuses on the student, as he focuses on the book and the teacher and the student is simply reproducing (It must be said that in the middle is the program that does not leave much space to deal concretely with a period and its representatives, e.g. In Italian texts of the same level, ancient literature, regional myths, etc. occupy the space of a year and concrete texts are 
analyzed. In the treatment of the Iliad in the section Text Study which is related to the information on the whole work from 13 half questions are of the character given by the above paragraph (These questions are to be noticed: 1. How Homeric works are viewed today through similarities and differences. 2. What the Iliad narrates. At what point in the Trojan War do events take place? 5. Where does the epic character of the Iliad come from? What are the main features of this epism? etc. (Pegi, p. 52.)

What impresses most about the following is that the Text Study section (which you noticed above and which included some questions about the information provided) is repeated at the end of each type of literary text, but already structured in such sections:

Meaning and explanation of the text

Analysis through examples

Reflection and evaluation of knowledge

The word and its use

\section{Assignments and tips}

Looking at them as glossary terminology we would notice that the last topic for us should be intertwined with the other topics.

We also believe that the name of the second section is implied at least in the first section and, on the other hand, is very evasive, as it does not clearly induce the type of analysis and the type of competence it intends to activate, since analysis as a methodology is used as a mechanism, both for reading, for speaking, for interpreting, and even for recreating it is very important that most tasks say Recreate by example.

By diving into each of the sections, questions that are not adequate for one section, as they are related to another (even if we take the latter for granted) are quite easily discernible. Thus in the Iliad in the section Meaning and explanation of the text the first point given asks the following questions:

Where does Achilles' anger come from? Why does the author care about the feeling of this knight? What kind of misfortune does his anger bring? (Pegi, p. 57)

It can be noted that the second question concerns the interpretation of the text by the student.

The second topic and its structuring confirm the fact that the analysis through examples requires more illustration for the effect of naming the rubric, than the illustration in the function of the analysis of the meaning, coherence, and cohesion of the text. Of the four questions, in our opinion, only the third question is related to the naming of the rubric (Analyse through the illustrations from the passage, the support they already give to the characters and events in the work. Pegi, p. 57), while the other three questions are related to either with meaning or interpretation (What is his role, Agamemnon, in the Hellenic army. Analyze the author's consideration for Agamemnon. Why is the interlocutor in Agamemnon's word Achilles? How is his reaction compared to that of the king?) [Pegi, f. 57]

It can be noticed that the second question has to do with the composition of the text and the interpretation of this coherence by the student.

The second rubric and its structuring confirm the fact that the analysis through examples requires more illustration for the sole effect of naming the rubric, than the illustration in the function of the analysis of the meaning, coherence, and cohesion of the text.

Likewise in the third section, which requires reflection and evaluation of knowledge, the second question of the first point explicitly requires figurative finding, even without its stylistic explanation related at least to the interpretation of the text as a whole and the two female figures of their role in the 
text in particular (Find and explain the epithets by which he refers to Chrysida and Briseida.) [Pegi, p. 57]

We are not adding here that in fact, it is not only the epithets but a set of structures that give both the attitude of the characters and the author about them and not just the epithets.

The last section is completely unstructured according to us, as it requires detached information related to detached identification and interpretation of units, be they figures (epithets) unrelated to the general interpretation of the cohesion of the work. Perhaps this also comes from the influence of the tradition of these texts that give the figuration with detached units. Such a thing is already surpassed, as every unit, even if incomplete in superficial structure, in deep structure exists within a structure, where it receives certain denotative and connotative values. (Discuss the function of compound adjectives: long-sighted, magnifying glass, eye-catcher, etc. Pegi, p. 57).

It is noteworthy to be said that the attempt to have two rubrics related to the analysis (regardless of how they are realized concretely), i.e., that of analysis through illustrations and that of speech and its use is positive.

On the other hand, it is obvious the lack of oriented characterization of the second rubric in the type of analysis that should have included both that of meaning and that of composition.

Also, in the section Reflecting and evaluation of knowledge, interpretation of the text is even more required than reflection and presentation of the individual opinion of the student. (On which of their attributes, Chrysida and Briseide, does he, Agamemnon, rely on, to distinguish them? Find and explain the two epithets by which he refers to them. Explain the wisdom of the king and the importance of the supremacy of duty over personal desires, through Agamemnon's tolerance in this song. Pegi, $\mathrm{p}$. 57).

It would be quite good to suggest contrasting methods here, ie to seek reflections in approach to other similar texts that students have made (here our Epic).

We determine that reflection does not necessarily need to exist solely for its meaning, messages, images, etc., but also the composition, to stimulate in the student his creative competence.

\section{Discussions on the problems identified in the pedagogical apparatus}

At the end of this analysis, we can state that the problems encountered most in the method of analysis of the above three texts are as follows:

\subsection{Queries regarding the transition from meaning (decipherment) to interpretation}

About $80 \%$ of the analysis apparatuses identify this fact, which in fact appears to be intertwined with the follow-up problems.

\section{Examples from Albas, rubric Reflecting for the meaning:}

(Iliad-Homer) The first verse of the Iliad poem has served as a model for all epic poems up to our era. The poet addresses the deity or the muse so that with its inspiration and support he can successfully complete his poem. Remember other introductions of epic poems or songs from the Albanian epic "Kangë kreshnike", or from the Fishtian epic "Lahuta e Malcis" (p. 54)/ (Medea Euripidi) Shpjegoni konfliktin e dyfishtë të tragjedisë: atë të Medeas me Jansonin dhe atë të Medeas me veten. (p. 88)/ (Meshari-Gj. Buzuku) Si mund ta interpretoni lidhjen ndërmjet dashurisë së të rinjve dhe lulëzimit të pranverës? Është kjo një lidhje thjeshtë e jashtme, apo e brendshme? (p.177) 


\section{Examples from Filara: rubric Understanding the text:}

(Gjergj Elez Alia-Folklore) The keywords in this excerpt create a picture: brave sword, mace, blood, square? (p. 74)

(Divine Comedy-D. Aligeri) The end of Ulysses and his companions resembles an apocalyptic end. Underline the details that enhance this visual and acoustic imagination at the same time. (p. 151)

(Skanderbeg Story-M. Barleti) The speech begins with a contradictory sentence. Underline them in the text and explain the importance of these sentences. Do they help convince senators? (p. 168)

\section{Examples from a textbook of Pegi:}

We determine that this point of Pegi has been accomplished since the title of the first rubric, in which the meaning and explanation of the text are sought. (Medea-Euripides): How do you comment on the verse: But as human beings, we must endure every calamity. Pegi, p. 87)

Likewise, in the rubric related to the reflection and evaluation of knowledge, some points require interpretation of the fragment of the text (Based on the given fragment, describe the complexity of the figure of Medea. Pegi p. 87). In Prometheus, respectively in the rubric Meaning and explanation, the text finds, among other things, these points which, in our opinion, require interpretation of the structure of coherence and its specific content: The important part of the subject of the tragedy is the dramatic conflict and the moment when it is discovered or created. How does this conflict come about and where does it come from?;

In the same section, he finds the question: Is this the quality of a true ruler (it is related to the ingratitude of Zeus to Prometheus), [Pegi, p.73].

\subsection{Mismatch of questions between sections}

The identification of meaning in section I does not follow the interpretation of the identified identifications (section II). We can say that in all three texts we encounter this problem in different percentages. It is more than common to encounter questions about interpretation, or simply illustration where the meaning of a structure or a meaning is sought. Likewise, in many cases, you encounter questions that require reflection or interpretation in a section that is about understanding. Example from Filara: (Medea-Euripides) From the section Understanding the text is the first question Euripides lowered the mythological heroes to the level of ordinary people, stripped them of epic and ideal magnificence. Find in detail the details that illustrate this idea. While in the next section Analysis of the text we encounter the request Find in the excerpt all the epithets with which Medea addresses her husband and makes an analysis of her character (p. 132). From the text of Albas in the rubric related to the meaning (number 2), we encounter the question (Prometheus stuck-Aeschylus) Who is the punisher of Prometheus: Hermes or Zeus? Respectively in the following section of the interpretation, the question that had to be answered above does not connect the identification with the interpretation Prometheus, although related, emerges as a symbol of intellect and stability. Does this come from the fact that he is aware of the deed he has committed or that he is unconscious? Discuss this opinion (p. 74-75).

Albas. Rubric: Reflect on the interpretation. If we refer to the above requirement p. 54, having identified the formula of the epic (though unrelated to the meaning), none of the questions in the reflection section require continuity of analysis to decipher the data of the epic model. (PrometheusAeschylus) Comment on the last two verses of the passage: how Prometheus is presented to us through them (p. 75), a question that creates confusion between reflection and commentary. (Divine ComedyD. Aligeri) Based on the second part of the passage "Gates of Hell", try to give the exact Dantean 
meaning of the verse "Love does not allow dislike", (p. 128) request that is not related to the interpretation, but sends the student in understanding the text.

\subsection{An ambiguity of comment with interpretation}

Filara, for example, separates without any criteria the rubrics "Text analysis" from "Interpretation and linguistic and stylistic commentary" and joins them in the typology of the questions they ask. In fact, here we need to make a terminological clarification. If we look at the practice of analyzing the texts mentioned above, we notice exactly this problem that we mentioned, so the comment equals the interpretation. In our view, this conception is not just a terminological problem, but a methodological one, as these terms should not coincide with each other. In our opinion, the commentary should include both the process of content interpretation and the construction of the text, identifying in this context the way of organizing coherence and cohesion of a text, detailing these with finer elements of the stylistic microstructure of a certain text. In this context, the comment should include as an element the interpretation. From this point of view, Filara's text, by mixing the three rubrics, does not create a clear identification of the three phenomena, but divides them and retrieves them, in questions such as Comment on the following verses (appears in many passages), without giving any commentary instrument (e.g. pp. 110, 130) or text analysis with questions that lead to reflection: (Skanderbeg's story-Marin Barleti) Do you think apologizing is cowardice?; Where does Skanderbeg's merit lie in this part? (p. 174).

Even in the text compiled by the Pegi, it is more than common to find questions that do not belong to the section in which they are located. Thus, in the excerpt from Bogdani's Sibyls (Sibilat, Bogdani) in the section Analysis through examples, he finds this point: How the relationship between the religious and life views of the author is constructed in this poem. (Pegi, p. 112) which for us is more interpretation than analysis identified by examples.

In the following section Reflection and evaluation of knowledge finds this point: Bogdani is the creator of high poetic figures. In the given excerpt find and analyze one of them. (Pegi, p. 112). This point not only does not belong to the rubric but there are problems in the wording (note "high poetic figures"). As a term interpretation is not found in any of Pegi's rubrics, but we find nuances of this concept in the Meaning and explanation of the text, Reflection, and evaluation of knowledge, and even in other rubrics: What worries the poet the most is the question found in the rubric Understanding and text explanation? (Christian Doctrine, Pegi, p. 117)

What does the verse mean: Where are those generous elders? This is the question found in the section Reflection and Assessment of Knowledge (Christian Doctrine, Pegi, 117).

Courses related to the commentary on the concept given above in the section Reflection and explanation of knowledge finds such questions as How is this atmosphere conveyed through the apostrophe and antithesis, Comment on how the content is conveyed through different tones in the first and last stanza (Pegi, p. 117)

\subsection{The ambiguity of interpretation with opinion}

This point is also inherited from the problems that appear in point 3, as the interpretation is necessarily related to the text under analysis and should not be confused with personal opinions, even if they are based on certain clues from the text. (Such a fact is easily identifiable in various national tests where there are questions that require opinions and not interpretations based on textual data ${ }^{12}$.)

\footnotetext{
12 https://shqiptarja.com/lajm/analiza-e-dy-pedagogeve-ku-qendronin-gabimet-ne-provimin-matures-se-gjuhes-eletersise
} 
We can refer to examples from Albas: (Stuck Prometheus-Aeschylus), in the section Reflect on the structure we encounter the question How do you assess the role of the Choir in this passage? (p. 75), a question that has more to do with interpretation than with structure. (History of Skanderbeg-Marin Barleti), question: Express your opinion if Skanderbeg's speech is an example of an accurate and wise discourse (Albas, p.169); sends the student to the interpretation required by the rubric, deviating from the opinion required by the question.

Some examples from Filara: Rubric Interpretation and linguistic and artistic commentary: (Skanderbeg's story-M. Barleti) This analysis of his guilt and Skanderbeg's forgiveness is done to highlight the values that Moses had before or the values that Skanderbeg had and has? (p. 175) /(Don Quixote-Cervantes) If you were one of the characters in this chapter of "Don Quixote of Manche", in which of them would you find yourself? (p. 212) / (Hamlet-Shakespeare) How do you view Claudius' suffering and lack of remorse through this monologue? (p. 229).

In the section "Meaning and explanation of the text", by Pegi for Shakespeare's text "Hamlet" is found this point: "Explain the relationship between the Halmletian purpose and reality." that for us in this section which aims at reading, understanding, and explanation through identification this point and its answer can be considered more as the opinion of the student, rather than interpretation based on the logic of the text (Pegi, p. 188).

\subsection{Comment without commenting tools}

The student is asked to comment on his own, without any indicators, without any commenting tools, ie without orienting them towards the textual data that should give them the objective elements of text decoding. Examples from Albas: (Orestia-Aeschylus) Comment on the words of the Choir from the tragedy "Orestia" (p. 10) /(Folklore-anonymous) Comment on these verses in writing ... "(p. 99)

Examples from Filara: (Don Quixote of Manche-Cervantes) Comment on Sancho's definition of themselves in the words he exchanged with Don Quixote: "as a conceived creature built behind your face the flesh of your flesh" (p. 207); Comment on Don Quixote's call "Let what happens now happen, for I am stuck here and I am not shaking, physically and spiritually, ready to face Satan himself!" (p. 207) / (Hamlet-Shakespeare) Analyse through the verse the ambition for power. (p. 228)

The same feature is found in Pegi. Discuss the great Hamletian dilemma: To live or not to live that is the question. (p. 188); Evaluate the situation at the end of the song (p. 135) etc.

In Pegi's text Meaning and Explanation for Shakespeare's text "Hamlet" this point is found: Explain the relationship between the Hamletian purpose and reality (Pegi, p. 188). For us in this section which aims at reading, understanding, and explanation through the identification of this point, and its answer can be considered more as a student's opinion than an interpretation based on the logic of the text.

\subsection{The stylistic profile of a fragment or an author cannot be provided}

The compression of the texts and the way of separate analysis of the fragments of a long text does not allow the creation of a clear idea on the work of a certain author even if the analysis of that text was without imperfections.

During the treatment, the texts also require interpretive analysis of literary figures (Albas Folk lyrics) Stop at the repetitions of the lyrics. What is the purpose of using them? (p. 99) / (Skanderbeg's story-M. Barleti) Many rhetorical questions are used in Skanderbeg's speech. Find and analyze their syntactic construction (p. 170) / (Meshari-Gj. Buzuku) Find the stylistic figures that characterize the girl and the boy. (p. 177); Filara (Poem of misery-Migjeni Find the literary figures you know in this passage (p. 39) / (Medea-Euripides) Define the literary figures underlined in the text. Find the other 
literary figures in the passage (p. 133). There are many in Pegi's texts that do not have reference points related to this section (Medea, p. 87, etc.) There are other cases where those that are can be found in other sections, so, in Aeschylus in the section Analysis through illustrations you will find this point: Aeschylus was the first to introduce the choir to the scene, illustrating with examples the importance of this scenic element and showing how it affects .... (p. 73), but these are not related to the stylistic specifics of the authors being addressed.

\subsection{The formal structure is confused with the internal structure of a text}

So, in the texts, there is no difference in the requirements related to the coherence and cohesion of a text. And above all, even when some of this knowledge is given, they are seen detached from their common function in drafting the macrostructure and microstructure of the text. The classic case is the questions that require finding figuration, metric elements, etc. without seeking the stylistic explanation of this type of use. (Iliad-Homer) How does Priam's vocabulary change when he describes the coming of Achilles into battle and then Hector? Identify the words, expressions, and specific figures that give this difference; (Pegi, p. 61). (Stuck Prometheus-Aeschylus) Find opposite words to the above for the figure of Prometheus (Albas, p. 75). (Medea-Euripides) Define literary figures in the underlined words in the text. find other literary figures in the passage. Say what kind of figures they are (of meaning, expression, etc.). (Filara, p. 133).

These questions are commonly found in all three texts.

Furthermore, these texts are not clearly structured for an accurate analysis of the structure of the text and its content and they do not provide a satisfactory methodology to stimulate in the students themselves, the competencies claimed by the programs, which are based on the realization of certain competencies.

Looking at these issues in-depth, we suggested a model that can guide teachers (not necessarily exclusively) in the way in which they can approach a given text through four topics with classic names.

Table 1. Problems expressed in percentage for each textbook

\begin{tabular}{|c|c|c|c|c|c|c|c|}
\hline Problematics & $\begin{array}{l}\text { Queries } \\
\text { regarding the } \\
\text { transition from } \\
\text { meaning } \\
\text { (decipherment) } \\
\text { to interpretation }\end{array}$ & $\begin{array}{l}\text { Mismatch } \\
\text { of } \\
\text { questions } \\
\text { between } \\
\text { sections }\end{array}$ & $\begin{array}{l}\text { An ambiguity } \\
\text { of comment } \\
\text { with } \\
\text { interpretation }\end{array}$ & $\begin{array}{l}\text { An ambiguity } \\
\text { of } \\
\text { interpretation } \\
\text { with opinion }\end{array}$ & $\begin{array}{l}\text { Comment } \\
\text { without } \\
\text { commenting } \\
\text { tools }\end{array}$ & $\begin{array}{l}\text { The stylistic } \\
\text { profile of a } \\
\text { fragment or } \\
\text { an author } \\
\text { lack of } \\
\text { achievement }\end{array}$ & $\begin{array}{l}\text { Mix-up } \\
\text { of the } \\
\text { formal } \\
\text { structure } \\
\text { with the } \\
\text { internal } \\
\text { structure } \\
\text { of a text }\end{array}$ \\
\hline $\begin{array}{l}\text { Percentages } \\
\text { Albas }\end{array}$ & $60 \%$ & $50 \%$ & $80 \%$ & $50 \%$ & $20 \%$ & $90 \%$ & $30 \%$ \\
\hline $\begin{array}{l}\text { Percentages } \\
\text { Filara }\end{array}$ & $80 \%$ & $70 \%$ & $90 \%$ & $70 \%$ & $60 \%$ & $90 \%$ & $70 \%$ \\
\hline $\begin{array}{l}\text { Percentages } \\
\text { Pegi }\end{array}$ & $80 \%$ & $80 \%$ & $90 \%$ & $80 \%$ & $70 \%$ & $90 \%$ & $90 \%$ \\
\hline
\end{tabular}




\section{Conclusions}

At the end of this paper, we can certainly conclude that the issues identified in the text analysis apparatus of Grade 10 in all winning publishing houses are quite serious. The model of student they create is of a recreating and memorizing type rather than stimulating the student at the center of the lesson and guide them with the help of the teacher. (the likes of which may be discussed), which when organized with orientation sub-points, suggest ways in which they can be adapted for a good analysis of the text, according to the stylistic features it displays and, on the other hand, will equip the student with specific competencies that will allow them to decode the message, structure, interpretation of the two, as well as the expression of personal opinions about the text.

Our model aims to provide an aid especially in linking the identification of the structure of a text to its message, thus serving as part of the compositional cognitive competence that will give students the elements of recreation, whether according to the model of the text taken into the analysis, whether by combining the latter with its original stylistic elements.

Wrongful interpretations of the ways in which a text is woven into the examined texts that were generally related to figurative findings, without its stylistic explanation have been avoided in our model as a knowledge that does not serve the decoding of different levels.

To contribute to the improvement of this reality we suggest to the teachers interested in professional networks and a model of analysis, from which a clear idea of the belonging of the rubrics can be created and at the same time their stimulation towards a student-centered class, which makes them active, analytical, interpretive, reflective, and also creative.

\subsection{Model}

The model that we think should be analyzed in a literary text, should initially focus on creating competencies, as well as go through the intentional reading processes, which we listed earlier. This is not an unknown pattern for the way a literary text is viewed. We have referred and consulted several textbooks which have been used over the years in schools of the European community, but adapting to the specifics of Albanian teaching, of course also social and didactic instruments familiar in the field of Albanian students and teachers.

Modeled according to the specifics of the text, the format we offer goes through several sections, which are managed by the authors of the textbooks following the nature of the selected passages. There are two goals of the model we offer:

a-Achieving optimal levels of integrated competencies;

$b$-The functionality of the rubrics and the use of equally functional terminologies.

Macro-rubrics are composed of analytical segments based on accurate scientific terminology and built according to standardized levels of competence achievement.

\subsubsection{Reading}

The constituent sections of the macro rubric are divided into two levels of absorption of the textural material:

Knowing how to read

This section orients the first read through which aims to achieve the minimum competence, understanding the first and second level of teaching. The student needs to understand why the passage is spoken to create the right images and perceptions on them. The routes through which these information passes are: 
-understanding the lexicon;

-individualizing specific textual information;

- understanding the information that the text does not say;

- being able to connect information between them and beyond;

- highlighting the relations of cohesion and coherence in the text;

- reconstructing the general meaning;

-interpreting and evaluating the text;

These areas are achieved with the first and second textual reading. This way, the student achieves the right perceptions that pave the way for perceptions as a reader.

\section{Reading to learn}

In this section the student is trained for the reading process at the highest interpretive levels, initiated by formal and structural indicators:

- Reading the way of weaving the text (form and content of a text, its compositional organization both from the structural and semantic point of view);

- Understanding the structure of a book page and an excerpt;

- Providing a meaning based on the characteristics of the expressions;

- Moving from the text to the file and from the latter to the oral presentation;

We determine that this course is inalienable because only after they have managed to understand a text, a student will ensure the reading of the signs he offers, as well as clarify its formal and internal structure. Compatibility is created between the two rubrics, giving students the right skills to move on to text retrieval processes.

\subsubsection{Speaking}

This section aims at an exploratory re-reading of the text, through which the interpretation and identification of stereotypical construction tools are aimed.

Due to it being built for focusing on the paraphrasing of the passage, through the steps provided by this section, the student reports data on the lexicon, interpretations of formats and syntactic segments, and the collection of discourses that the first text does not say directly.

\section{Working with the lexicon.}

This reading process encapsulates the need for articulation through a broad but consistent lexical text lexicon. This articulation inclines the student towards working with the lexicon embedded in the textual structure and focusing the semantic field in accordance with the principle of the intentionality of the saying.

-Expanding the lexicon;

-Building semantic fields within the fragment;

-Understanding and reusing lexis in other contexts.

The paraphrasing realized with the moderation of the means of communication ensures the integration between the linguistic and the literary competence.

\section{Understanding and using statements/phrases}

Closely related to the discourse, the student's knowledge is displayed in practical situations and processed through strategies aimed at expanding the semantics of words:

-Distinguishing familiar words from unknowns and intersections of semantic fields;

- Identifying the contextual meaning and bringing them back to other contexts;

-Consulting the dictionary and determining the meaning inside and outside it;

-Confronting vocabulary data with contextual semantic uses, recognizing misunderstandings, then avoiding personal articulation. 


\section{The relation between meaning and word}

This is the moment when the text is seen segmented and whole at the same time. Such a functional proceeding has drawn the student deep into the semantic relations and interpretive relations that they themselves establish with the saying. The text is seen as a macro, within which communication mechanisms and areas of communicative relations function:

-to identify synonyms, antonyms, homonyms, the polysemy of words;

- to make lexical choices in the connections of words with communicative purposes;

-manipulate the text by picking up the productive lexicon (replacing words with the right synonyms, replacing words with greater usage density) and using the product achieved to summarize, paraphrase or explain the text;

-determine the figurative meaning of words (denotative and connotative meaning, figurative language, and the purpose of communication through it).

Once we have overcome these stages that involve some cognitive processes in them, we understand that the student has not only acquired communication skills but has extended his mental activity to other areas such as sociolinguistics, psycholinguistics, and obviously what prevails are the pragmatic knowledge which is decisive throughout this process.

In an integrated way, within the rubrics and lying in them, the very important process of knowledge recycling, but in the writing, space is the macro rubric.

\subsubsection{Writing}

Throughout the processes that accompany this section, the student enables another form and content of articulation, which cannot be understood or treated separately from the first two, because the connection with them is conditioned by the communication process itself.

\section{Knowing how to write}

Writing almost never comes from anything. In literature, research on intertextuality has taught us that every writer works with a textual tradition; journalists work on news, information, personal note; professional relationships start with preliminary materials, etc. Even in school, priority is given to texts written by other texts. Therefore, this is the case when on the given contents, the writings which start generating those contents in other forms begin.

\section{Writing to learn}

- to answer questions;

- to write open-ended and closed-ended questions and reciprocally provide the types of answers;

- give a coherent answer to the question;

- select out exhausted responses.

From the reader to the writer

This section concludes the language proficiency acquisition process and ensures maximum achievement of competencies. If from this step the student manages to conceptualize a complete text, with genuine literary and linguistic objectives, then the realization of the goal of the learning process and the achievement of his skills and competencies as a good and correct Albanian speaker is ensured:

- to produce your experience on the reading process;

- to give a narrative structure;

- to know the times of the story and to concretize them within the fragment;

- to have a narrative background and facts;

- to master the components of the story (purpose of writing, planning, rewriting)

- to write different writing typologies:

- to write descriptions (using elements taken from the given text; using different rhetorical figures) 
- to write by fantasizing (use of language games, animation, and transformation, the extraordinary within the ordinary)

- to compile narrative texts (to individualize the information, to reformulate it, to summarize it with different purposes);

- to write different typologies of literary texts;

Such a formation on several levels presented in our model (which refers to European practices such as Italian and French) we think encourages the student and interpretive-presentation skills, which is generally lacking in the texts currently in their hands.

We are aware that our suggestions and the model given by us do not exhaust the entirety of the problems. However, they aid dedicated teachers who have been debating and seeking solutions to such issues for years, which concern them professionally.

Table 2. The content of the pedagogical apparatus according to the specific weight of the glossary within the lesson

\begin{tabular}{|c|c|c|c|c|c|c|c|}
\hline Part I- 30\% & & Part II- 35 & & & Part III- 3 & & \\
\hline Reading & & Speaking & & & Writing & & \\
\hline $\begin{array}{l}\text { Knowing } \\
\text { how to read }\end{array}$ & $\begin{array}{l}\text { Reading to } \\
\text { learn }\end{array}$ & $\begin{array}{l}\text { Working } \\
\text { with the } \\
\text { lexicon }\end{array}$ & $\begin{array}{l}\text { Understanding } \\
\text { and using the } \\
\text { expressions }\end{array}$ & $\begin{array}{l}\text { The ratio } \\
\text { among the } \\
\text { expression } \\
\text { and the } \\
\text { word }\end{array}$ & $\begin{array}{l}\text { Knowing } \\
\text { how to } \\
\text { write }\end{array}$ & $\begin{array}{l}\text { Writing } \\
\text { to learn }\end{array}$ & $\begin{array}{l}\text { From the } \\
\text { reader to } \\
\text { the writer }\end{array}$ \\
\hline $10 \%$ & $20 \%$ & $5 \%$ & $15 \%$ & $15 \%$ & $5 \%$ & $20 \%$ & $10 \%$ \\
\hline
\end{tabular}

\section{Ethics Committee Approval}

The author(s) confirm(s) that the study does not need ethics committee approval according to the research integrity rules in their country (Date of Confirmation: 05.04.2021)

\section{References}

Benvenuti, G. \& Ceserani, R. (2012). La letteratura nell'eta globale. Universale paperbacks. Il Mulino.

Damrosch, D. \& Pike, D. (2009). The Longman anthology of world literature (The Ancient World, The Medieval Era, and the Early Modern Period). Pearson/Longman.

Damrosch, D. (2003a). What is world literature? Princeton University Press.

Damrosch, D. (2009b). How to Read World Literature. Chichester, Wiley-Blackwell.

Plangarica. T. (2018). Aspekte të gjuhësisë së zbatuar II. Akademia e Studimeve Albanologjike, Instituti i Gjuhësisë dhe Letërsisë, Tiranë.

Serianni. L. (2019). Il sentimento della lingua. Il Mulino.

Da Re, F. (2013). La didattica per competenze. Pearson Italia, Milano - Torino.

Levati, W. \& Saraò, M. (1998). Il modello delle competenze. Franco Angeli, Milano.

Regione Emilia Romagna. (1997). Glossario dei termini utilizzati nei documenti di lavoro elaborati per la predisposizione delle politiche formative. 
OCDE. (1966). Qualifications et competences professionnelles dans l'enseignement technique et la formation professionnelle. Évaluation et certification, Paris.

Le Boterf, G. (1994). De la competence. Les éditions de l'Organisation, Paris.

Chomsky. N. (2006). Language and mind. Cambridge.

Hamiti, S., Marashi, A. \& Shehri, Dh. (2017). Letërsia X. Albas.

Spaho, V., Kajo V., Kapllani, M., Neni, M. \& Ballici M. (2017). Letërsia X. Filara.

Çiraku, Y., Lami, A., Lamaj, I., Macaj, E. \& Sula, A. (2017). Letërsia X. Pegi.

Ferri, Ch. \& Matei, L. (2016). Giallo, rosso, blu-tre colori per tre livelli de difficolta. Mondadori scuola,;

Ríos, C., Frugoni, F., Trezza, A. \& Dalmaroni, M. (2012). Leer literatura en la escuela secundaria, Propuestas para el trabajo en el aula. Buenos Aries Education.

Lycées, F. (2000). Methodes et activités littéraires. NATHA/HER.

Pouzalgues, J.\& Taillac, Ch. (1996). Franchais, Methodé \&Techniques. Nathan.

Mariotti, A., Cioncetta Sclafani, M. \& Stancanelli, A. (2000). Nuovo quatro colori (libro giallo, verde, rosso, blu). Casa editrice G.d`Anna Messina Firenze.

\section{Website}

http://www.instat.gov.al/al/temat/tregu-i-punës-dhe-arsimi/arsimi/\#tab2

https://ascap.edu.al/ëp-content/uploads/2019/01/Gjuhë-shqipe-3.pdf

http://lineadidattica.altervista.org/files/LA-DIDATTICA-PER-COMPETENZE.pdf

https://ww.hoepli.it/libro/il-modello-delle-competenze-/9788846405012.html

https://en.calameo.com/books/000450277a5f85fead377

https://site.unibo.it/griseldaonline/it/didattica/carla-sclarandis-letteratura-italiana-nuovi-italiani

https://site.unibo.it/griseldaonline/it/didattica/carla-sclarandis-leopardi-scuola-competenze

\section{AUTHORS BIODATA}

Natasha Poroçani (Ph.D.) is a full-time lector at the University of Durrës, Albania. Her interests are in pragmatics, discourse analyses, and she is an education expert.

Albana Deda (Ph.D.) is a full-time lector at the University of Tirana, Department of Linguistics for 22 years. Her interests are in morpho-syntax and stylistics. 